\title{
An Academic Reflection as an Examination after High-Fidelity Simulation in Nursing Education
}

\author{
Elenita Forsberg, Karin Rasmusson \\ School of Health and Welfare, Halmstad University, Halmstad, Sweden \\ Email: elenita.forsberg@hh.se
}

How to cite this paper: Forsberg, E., \& Rasmusson, K. (2020). An Academic Reflection as an Examination after High-Fidelity Simulation in Nursing Education. Creative Education, 11, 2806-2821. https://doi.org/10.4236/ce.2020.1112206

Received: November 19, 2020

Accepted: December 21, 2020

Published: December 24, 2020

Copyright $\odot 2020$ by author(s) and Scientific Research Publishing Inc. This work is licensed under the Creative Commons Attribution International License (CC BY 4.0).

http://creativecommons.org/licenses/by/4.0/ (c) (i) Open Access

\begin{abstract}
Introduction: Today's healthcare is complex and the need for quick decisions and care can be crucial for the patient's well-being. For the students, it is essential to develop clinical competence during their nursing education. Aim: The aim of the study was to explore how an individual written academic reflection as an examination after high-fidelity simulation can support student nurses' learning experiences of clinical competence when a developed questionnaire was used to stimulate in-depth reflection. Method: After the intervention of using an academic reflection as an examination after high-fidelity simulation during the fourth semester of the nursing programme, 107 individually written academic reflections were collected from students during 2017-18. A questionnaire with seven open-ended questions was developed to stimulate the reflection of students' learning experiences of clinical competence. Based on Kolb's experiential learning cycle, a deductive content analysis was used with focus on the students' learning experiences. Results: The students expressed that the performed simulated scenario in connection with the individual written academic reflection made them aware of the strengths and weaknesses in their ability to clinical reasoning and patient safety. Furthermore, the importance of communications skills emerged. The students highlighted the use of the closed loop structure for communication in the team, and the necessity to involve the patient more in clinical situations. During the simulation scenarios, the students appreciated in having the opportunity to be an observer for developing knowledge concerning clinical competence. Conclusion: By implementing an examination that provides an opportunity for time for an in depth-reflection, creates effectively professional development. The academic reflection as an examination appears to be a good learning experience such as the clinical competence became visible for the students. Integrating reflective writing continuously during the nursing education can contribute progression of students' skills to write an academic reflection.
\end{abstract}




\section{Keywords}

Academic Written Reflection, Clinical Competence, Examination, Learning Experiences, Nursing Education, Simulation-Based Training

\section{Introduction}

This study explores the impact, an individual written academic reflection can have upon learning of clinical competence, as an exam after high fidelity simulation in nurse education. To develop clinical competence is essential for student nurses. The concept of clinical competence includes clinical reasoning, communication skills, attitudes, clinical skills and acting patient safe (Notarnicola et al., 2016). Today's healthcare is complex and the need for a quick decision and care can be crucial for the patient's well-being (Aiken et al., 2014). By developing the nurse's profession and ability for clinical reasoning, both the theoretical connection and an evidence-based approach can be strengthened. One of the challenges for healthcare today is to reduce the gap between what we do and what we should do based on the evidence-based knowledge available. Further, there is a requirement that health care should be provided with good and safe care (Aiken et al., 2017).

In Sweden, undergraduate nursing education is a three-year (180 credits) bachelor programme that leads to a license to practice as a registered nurse. The nursing education is a professional academic training programme, which requires knowledge, and skills that guarantee the quality of professional competence and has learning outcomes such as demonstrated clinical skills in nursing and medical sciences. The examination is a part of the learning process and should, therefore, be designed to train and prepare for the future professional function. In this study, the students participate in a final high-fidelity simulation as actors and observers and write individually an academic reflection afterwards. An important factor of experimental learning is situated learning and reflection, i.e. the process of learning through experience (Kolb, 1984), please see Figure 1. Situated learning refers to learning from a specific situation in this study from

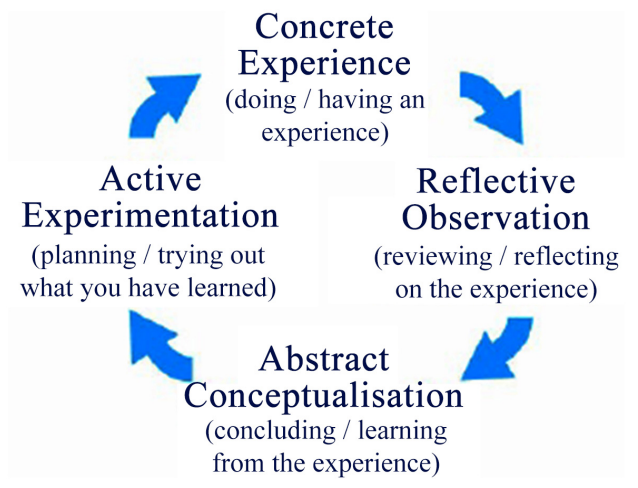

Figure 1. The experiential learning cycle (Kolb, 1984). 
the simulation scenario. It is well known that reflection upon experiences support learning and development. Reflection can be linked to reflection in action, on action and for action (Schön, 1983). According to general national learning goals recommended by Higher Education in Sweden, the student should demonstrate the ability to identify his or her need for further knowledge and to develop competence. Such a goal requires the ability to reflect.

Nurses with shortcomings in clinical reasoning risk deteriorating the patients' health (Aiken, Clarke, Cheung, Sloane, \& Silber, 2003). Therefore, to be prepared for the nursing profession, it is importance to practice, learn and develop clinical reasoning skills during the education (Jessee \& Tanner, 2016; Johannesson, Silén, Kvist, \& Hult, 2013). Nurses clinical reasoning can be defined as "the cognitive processes and strategies that nurses use to understand the significance of patient data, to identify and diagnose actual or potential patient problems, to make clinical decisions to assist in problem resolution, and to achieve positive patient outcomes" (Fonteyn \& Ritter, 2008: p. 236). However, to teach and learn clinical reasoning is complex. It is difficult to make the clinical reasoning visible and for the students to grasp (Delany \& Golding, 2014). Levett-Jones et al. (2010) have developed the educational model: The five rights of clinical reasoning, which refers to the ability to collect the right cues, take the right action, for the right patient, at the right time for the right reason. Using the model aims to improve nursing students' ability to identify and manage clinically at-risk patients.

By providing good and safe care from a patient safety perspective, according to the Patient Safety Act (2010: p. 659), patients must be protected from receiving injuries in connection with being treated in both public and private care. To increase patient safety, it is important to involve the patient in all communication. The nurse plays a central role in the patient-centered work, as the profession is responsible for the nursing care (Aiken et al., 2014). This includes contributing to a good and safe nursing care for the patient, by preventing ill health and early attention to risks and changes that can lead to injuries. To ensure structured communication in the team, there are various methods to use, such as CRM principles (Crew Resource Management) and closed loop (Østergaard, Dieckmann, \& Lippert, 2011). Communication in the teams are characterised by trust, respect, and collaboration. All the team-members are working together to achieve the goal (Hellier \& Davidson, 2018).

In nursing education simulation-based training is a common feature. Highfidelity simulation with included debriefing can support the student to link theoretical knowledge into practical skills (Wotton, Davis, Button, \& Kelton, 2010). Debriefing provides reflection on actions and decisions taken during the scenario (Shinnick, Woo, Horwich, \& Steadman, 2011). By introducing various forms of simulation-based training, students are given the opportunity to train the professional skills and the ability to collaborate in a safe and secure environment at a clinical training center (Wotton et al., 2010). Focus upon simulation-based 
training can vary based on the needs and goals in the course. It can be training various technical aspects, practicing the communication in the team or clinical reasoning as part of the patient safety work. In a study by Wotton et al. (2010), nursing students demonstrated that they experienced broader learning opportunities when they were given cognitive, associative and psychomotor skills during the simulation-based training. According to Okuda et al. (2009) simulation-based training gives a better result than through traditional lectures or problem-based learning.

Writing an academic reflection can contribute to learning and professional development (Pelger \& Larsson, 2018). A personal reflection often describes events and feelings, while an academic reflection involves a conscious and stated purpose and shows evidence of learning (Moon, 2006). Academic reflection is a complex form of writing which involves different text types; chronological descriptions of events, theoretical reasoning, explanation, analysis as well as a discussion of the importance of their own experience for future practice (Ryan, 2011). This type of purposeful reflection (academic), which is a generally aim in higher education must ultimately reach the critical level for deep, active learning to occur.

Our intention was to develop an examination that made clinical competence visible for the student nurses and raise awareness of their own learning. Few studies have examined the impact an individual written academic reflection as an examination after high-fidelity simulation-based training can have on students learning in the nursing education. In the area of simulation-based training in nursing, several studies have indicated the need of developing models for post-simulation debriefing to promote deeper reflection (Alhaj Ali \& Musalam, 2018; Eikeland Husebø, Dieckmann, Rystedt, Søreide, \& Friberg, 2013; Lestander, Lehto, \& Engström, 2016).

\section{Aim}

The aim of the study was to explore how an individual written academic reflection as an examination after high-fidelity simulation can support student nurses' learning experiences of clinical competence, when a developed questionnaire was used to stimulate in-depth reflection.

\section{Method}

\subsection{Design}

A descriptive qualitative design (Bryman, 2016).

\subsection{Sample}

This study is related to a 10-week course in the fourth semester in the nursing education and represents work-place training at hospital. Three classes with a total of 109 nursing students at a university in Sweden participated in an individual written academic reflection as an examination after high-fidelity simula- 
tion during 2017-2018. In the autumn of 2017, 34 students participated, in the spring of 2018, 41 students participated, and in the autumn of 2018, 34 students participated. In connection with the second simulation-based training in the end of the course, the students received information about the study. If they wanted to participate voluntarily, they signed an informed consent. After assessment of the individual written academic reflections and informed consent from $107 \mathrm{stu}-$ dents, the academic reflections were deidentified, coded and analysed. The age of the participated students, 13 male and 94 women, ranged between 21 - 51 years, with a median age of 28.8 year.

\subsection{Intervention and Procedure}

In the beginning of the course, students completed a simulation scenario regarding a critical situation. The simulated scenario took place at the clinical training center at the university. Three teachers facilitated the scenarios; as voice of the patient (mannequin) or voice of the physician, controlling selected mannequin actions and responses, and observe students' drug administration in the room behind. The students were divided into groups of three actors and three observers. The actors conducted a high-fidelity simulation for one hour including debriefing. The observers sat in a room behind and saw the scenario on a video streaming screen. As observers, the students kept an eye on the actors' abilities of clinical reasoning, patient-safety (as patient-identification, basic hygiene routines, medication administration) and communication skills (as companionship, leadership and closed loop). The students then changed roles.

The new intervention in the course was to have a second simulation scenario in the end of the course with an individual written academic reflection afterwards. Before this final simulation-based training, the students were encouraged to be prepared to meet a patient with; sepsis, acute abdomen, diabetes and heart or respiratory insufficiency. The students should also be aware of laws and regulations regarding patient safety and medication administration.

Afterwards, the students were instructed to make an individual written academic reflection upon their learning and progression based on seven open questions in a learning platform survey and submit electronically to the examiner within 48 hours. In order to be approved, the students should answer the seven open-ended questions in the questionnaire, use first person voice and connect the reflection to relevant literature.

\subsection{Instrument}

The questionnaire was developed by the teaching team in the course and inspired by the Pelger \& Santessons (2017) report at Lund University.

The following questions with open-ended answers were used:

1) Please reflect what you did well during the simulated-based scenario. What significance did it have for the scenario and how can you use this experience in your future profession? 
2) If you were able to redo the simulated-based scenario what would you like to change? How can you use this experience in your future profession?

3) Describe your role in the team and your experience. Is there anything you would like to do differently? Please motivate.

4) Please reflect of your clinical reasoning during the simulated-based scenario. How has the clinical reasoning ability developed from the first simulationbased training, in the course?

5) What did you learn from the scenario and the feedback you received? Were you able to identify any needs for additional knowledge and skills? What goals would you set up to develop additional clinical competence?

6) In one of the simulated-based scenarios you have acted as an observer. Please describe your experience and the possible use for your learnings.

7) Reflect in what way you are better prepared for your profession? Please motivate

The reflection was not judged by content regarding a better or worse experience, but the students must demonstrate the ability to reflect upon their own learning. For example: they should not only write "I have been better at clinical reasoning", we wanted to see a distinct reflection, the student should reflect and describe how he/she did before and how he/she did now and motivate why (contrast and analyse) therefore next time "I will...".

\subsection{Analysis}

Qualitative content analysis was applied (Graneheim, Lindgren, \& Lundman, 2017). The individual written academic reflections were individually read and re-read by the authors to obtain an overview of the students' reflection of their learning experiences. A deductive approach was used from Kolbs, Experiential Learning Theory ([ELT] Kolb, 1984, please see Figure 1) with a focus on the students learning experiences of clinical competence. Situated learning refers to learning from a specific situation; in this study, the students derive the Concrete Experience from the completed simulation scenario, which creates the base for further learning. In the next step, the students undergo a Reflective Observation. Through the seven open-ended questions in the questionnaire, they reflect on the experience and an immediate understanding of the concrete experience is processed and related to students' previous cognitive structures. Reflection implies that the students can gain actual experience in a deeper way so they can formulate an understanding of abstract concepts, Abstract Conceptualisation. In the individual written exam i.e. in the academic reflection, the students conclude learning from the experience and then implementing what they have learned, and how they can use the deeper understanding in future clinical situations $A c$ tive Experimentation.

Meaning units from the individual written academic reflections were extracted according to the aim and then condensed and coded. Preliminary sub-categories and categories were developed and were discussed between the authors until reaching a consensus (please see Table 1). 
Table 1. Example of analysis process.

\begin{tabular}{|c|c|c|c|c|}
\hline Meaning units & Condensed meaning units & Codes & Subcategories & Category \\
\hline $\begin{array}{l}\text { I did well with thinking ahead } \\
\text { and inserting a peripheral line } \\
\text { right away, since I saw the } \\
\text { symptom of sepsis and knew } \\
\text { the patient would need both } \\
\text { infusion and intravenous } \\
\text { antibiotics. }\end{array}$ & $\begin{array}{l}\text { thinking ahead and insert a } \\
\text { peripheral line right away, since } \\
\text { I saw the symptom of sepsis }\end{array}$ & $\begin{array}{l}\text { Strength of clinical } \\
\text { reasoning }\end{array}$ & Identify areas of strength & $\begin{array}{l}\text { The ability to clinical } \\
\text { reasoning became visible }\end{array}$ \\
\hline $\begin{array}{l}\text { Even though checking the } \\
\text { patients breathing and } \\
\text { respiratory is a first priority, I } \\
\text { focused on the patient's } \\
\text { problem with the bladder.. }\end{array}$ & $\begin{array}{l}\text { patients breathing and } \\
\text { respiratory is a first priority, I } \\
\text { focused on the patient's } \\
\text { problem with the bladder }\end{array}$ & $\begin{array}{l}\text { Weakness of clinical } \\
\text { reasoning }\end{array}$ & Identify areas of weakness & \\
\hline $\begin{array}{l}\text { My ability to see the connection } \\
\text { between different parameters } \\
\text { and how they affect each other, } \\
\text { has got a lot better. After the } \\
\text { scenario I feel my ability to look } \\
\text { at the whole situation, has } \\
\text { improved greatly. }\end{array}$ & $\begin{array}{l}\text { My ability to see the connection } \\
\text { between different parameters } \\
\text { and how they affect each other, } \\
\text { has got a lot better }\end{array}$ & $\begin{array}{l}\text { Progression of clinical } \\
\text { reasoning }\end{array}$ & $\begin{array}{l}\text { Identify areas of } \\
\text { progression }\end{array}$ & \\
\hline
\end{tabular}

\subsection{Ethical Considerations}

Students were informed both verbally and in writing about the study. If agreeing to use the academic reflection for analysing data, the student signed a written informed consent. After the exam, the academic reflections were deidentified and coded. The study was related to normal course improvement, and thus did not need any ethical approval. Data is stored and handled in accordance with the EU General Data Protection Regulation (GDPR).

\section{Results}

The results showed that the implementation of a second simulation occasion in the end of the course, in connection with an individual academic reflection, afterwards deepened and visualised the students' clinical competence. The result showed that it gave the students the possibility to reflect upon the learning objectives, to identify additional knowledge needs, and being able to formulate learning goals for further knowledge needs. The students also identified positive learning outcomes of being an observer. Three main categories with sub-categories have been identified (Table 2). The results of the categories are reinforced with quotes from the students.

\subsection{The Ability to Clinical Reasoning Became Visible}

The academic reflection as an examination forced the students to reflect upon their clinical reasoning during the scenarios. The students describe how they have been aware of areas of strength, weakness and progression in their own 
clinical reasoning. Further, the students expressed that they have appreciated being in the observer role from a learning perspective. They have been able to reflect upon their classmates' reasoning and actions and reflect upon their own possible actions.

\subsubsection{Identify Areas of Strength}

In the students' reflections, the strengths of clinical reasoning were described as that the students' ability to combine theory and practice has improved. Students were able to quickly identify problems based on the patient's symptoms and vital parameters and then implement adequate actions.

"I did well with thinking ahead and inserting a peripheral line right away, since I saw the symptom of sepsis and knew the patient would need both infusion and intravenous antibiotics."

"When I came into the room the patient was unconscious with a 'snoring sound, so I made a quick decision to make sure the airways were opened."

"As an observer, I saw that they had good clinical reasoning, communicated well and came to action quickly."

\subsubsection{Identify Areas of Weakness}

In the students' reflections, it emerged that, for some students, it became clear that they had shortcomings in the clinical reasoning and, therefore, it took time for them to solve and act in the scenario. Some students have also reflected and become aware of the impact of stress in an emergency situation. The students described that they focused on symptoms that did not have the highest priority, which resulted in incorrect actions or of actions being delayed. In the role of observer, it became obvious how vulnerable the patient is and how easy it is to think and make mistakes, but you also learn from the mistakes of classmates. In the academic reflection, the students demonstrated the ability to formulate relevant goals for further knowledge acquisition.

"P $m$ not all that pleased with my clinical reasoning, I still feel a little hesitant .... and I guess that's why I didn't tie together the symptom with the diagnosis as quickly as my colleague."

"Even though checking the patients breathing and respiratory is a first priority, I focused on the patient's problem with the bladder ...."

Table 2. Categories and sub-categories.

\begin{tabular}{cc}
\hline Categories & Sub-categories \\
\hline $\begin{array}{c}\text { The ability to clinical } \\
\text { reasoning became visible }\end{array}$ & $\begin{array}{c}\text { Identify areas of strength } \\
\text { Identify areas of weakness } \\
\text { The importance of communication } \\
\text { skills became visible } \\
\text { The ability to act patient-safety } \\
\text { became evident }\end{array}$ \\
\hline
\end{tabular}


"As an observer, I saw how vulnerable the patient really is. I also saw how easy it is to forget that sometimes there are measures that can be taken directly, nursing-based actions that can facilitate the patient. You learn from the mistakes you see others make."

The students became aware of additional knowledge needs and set up goals such as;

"I need to rehearse theoretical knowledge about different diseases and make a continuous plan for rehearsal after different courses

I need more theoretical knowledge of emergency situations, so I know what to do."

\subsubsection{Identify Progression in Student's Own Clinical Reasoning}

In the reflections, the students described how they had developed clinical reasoning skills since the simulation training in the beginning of the course. The student's ability to a holistic perspective had increased and they expressed that they now could see their own progression. In the role as an observer, the nursing perspective had become broader.

"My ability to see the connection between different parameters and how they affect each other, has got a lot better. After the scenario I feel my ability to look at the whole situation, has improved greatly."

"My clinical reasoning has truly expanded after the course. $\mathrm{P} m$ able to ask myself important diagnostic questions depending on what the patient's symptoms are and the answers I get from the physical exam."

"It's a great feeling to know I have the knowledge and skill to handle different complex situations so well."

"I think acting as an observer is a very good way of learning. You see how others work, how they reason and how they think in different situations. Then you can think about what has been done well and what they have done a little worse and learn from their experiences. I also think you can learn to think in different ways and that you can do things in different ways, you get a broader perspective on how the nurse's work can be performed."

\subsection{The Importance of Communication Skills Became Visible}

Through the problem-solving process, and the actions taken under the simulation scenarios, the students have reflected upon the importance of communication in the team and the communication with the patient for good and safe care.

\subsubsection{The Need to Use Closed Loop}

In the student's reflections, the importance of effective communication in the team was emphasised. From a patient safety perspective, the benefit of using the closed loop structure was pointed out, so that everyone in the team was informed of what has been done and what the next actions are to take.

" $A$ big learning for me has been that communication between colleagues is very important, $1 \mathrm{~m}$ trying to be clear and give feedback to make sure everything 
is perceived. I often have a plan and it would be easier for everyone in the team to be useful and do their part, if I got better at"thinking out loud".

"It's beneficial if we as a team would take more breaks and use more of the closed loop so we were able to confirm that everyone understands and knows what's going to happen next."

"As an observer, the need of the closed loop becomes clearer-seeing how easy it is to miss something if you do not give feedback to the team and especially important in stressful situations."

\subsubsection{The Need to Involve the Patient}

In the academic reflection, the students expressed that they often forgot including the patient in clinical decisions and nursing care as it was a stressful situation. The students became aware of the importance of informing the patient before nursing actions and using a comprehensible language to the patient. Some students also described that they have communicated well despite the patient being unable to answer.

"We tried to keep the patient calm by not leaving the patient alone. Though should we have thought more about talking to the patient, but it was so stressful, so it was hard to focus on everything, which made us forget the patient."

"It is important not to forget to talk to the patient and adapt the language. Instead of saying a peripheral venous catheter to a panicked patient, it may be better to find another name."

"We told the patient what we were doing even though the patient was unconscious."

"As an observer, I am impressed by what actions they took which I myself did not thought of. The experiences I take with me are that they were very good at communicating in the team, sharing the work and talking to the patient."

The students became aware of additional knowledge needs and set up goals such as;

"To inform each other in the team, to think aloud and update each other and not forget to respond to the patient who is in a vulnerable situation."

"In the future, I will try to see and hear the patient even more and think about what I can do for the patient in every moment."

\subsection{The Ability to Act Patient-Safety Became Evident}

Through the problem-solving process and the actions taken under the simulation scenarios, the students have reflected and identified factors for patient safety. The students described that they had gained a better insight into what an emergency situation can be like and what is expected of them as nurses.

\subsubsection{Identify Areas of Strength}

To promote patient safety, students have identified the importance of having a team-leader, maintaining calmness, communicating with their colleagues as well as taking help from them to ensure that the patient receives the best possible 
care and that patient safety is maintained.

"The team worked well because we had identified roles such as a leader and follows. Further, we kept calm in the emergency situation, which made it possible to work more patient safety."

"I have gained a greater understanding of the importance of thinking aloud and motivating action as to give a structured report to colleagues for increased patient safety."

\subsubsection{Identify Areas of Weakness}

Most students easily identified areas of weakness in the ability to act patient safety. Several students described that they, during the simulation scenario, became aware of their own shortcomings in hygiene routines, patient identification, nursing technical skills and communication in the team.

"It is easy to forget to take patient identification in an emergency situation, but this must always be done. I burst into that when I gave a glucose injection without checking the patient's identification. It is not the knowledge that is lacking, more the ability to still get all details even in a stressed situation where you have to act quickly. Patient safety must never be forgotten."

"We failed in the application of basic hygiene routines even though we were better than at the previous simulation occasion. Checking patient identification was something we also missed before we administrated drugs and oxygen."

"As an observer it is very useful indeed to see how others act in different situations. You not only see shortcomings; you also get ideas about solutions and approaches you may not have come to yourself."

The students became aware of additional knowledge needs and set up goals such as:

"Working in teams with good patient safety is something I must continue to practice. In the future, after each situation, I will take the time to reflect on how it went, what was good or what was less good. Also, what I need to get better at next time. I want to train in emergency situations."

\section{Discussion}

In this study, we have explored the impact an individual written academic reflection as an examination after a high-fidelity full-scale scenario can have on the learning experiences of clinical competence. To provide support for in-depth reflection, a questionnaire with seven open-ended questions was developed. The academic reflection as an examination appears to be a good learning experience such as the clinical competence became visible for the students. Delany \& Golding (2014) have described that to teach and learn clinical reasoning in nursing is difficult and, therefore, educators need to implement learning activities which make it more visible and understandable for the students. The students expressed that the performed simulated scenario, in connection with the individual written academic reflection, made them aware of their own strengths and weaknesses in their ability to clinical reasoning and patient safety. Reflection after simulation- 
based training can help students to assess their strengths and weaknesses (Fey, Scrandis, Daniels, \& Haut, 2014). Furthermore, the importance of communications skills emerged. The students highlighted to use the structure of the closed loop for communication in the team, and the necessity to involve the patient more in the clinical situations. To increase patient safety, it is important to use the closed loop structure in the team (Østergaard, Dieckmann, \& Lippert, 2011) and involve the patient in all communication. Findings in Lestander et al. (2016) show that the students themselves identify that reflection on practice can contribute to patient safety.

During the simulation scenarios, the students appreciated having the opportunity to be an observer for developing knowledge regarding clinical competence. As observers, the students emphasised that it is very useful to watch how classmates act in different clinical situations; they see shortcomings, but were also impressed how classmates acted and from this got ideas about solutions and approaches they may not have thought of themselves. That is in common with findings in Lestander et al. (2016) were several students described that they learned a lot by watching other people's actions during the simulated scenario.

The results in this study, regarding the students' descriptions of performed scenarios and written academic reflection, made their ability to clinical reasoning, patient safety and communication skills visible. In the simulated scenarios (Concrete Experience) the students train these abilities, and in the written academic reflection (Reflective Observations) they recall the concrete experience, describe and reflect over causes and effects of taken actions in the simulated scenarios and evidence based upon proper actions through relating to relevant literature. The written academic reflection can contribute to reduce the gap between what we do and what we should do based on the evidence-based knowledge available. The learning cycle Abstract Conceptualisation might be associated to the results of the students' translating theoretical knowledge of clinical competence into clinical practice. Connected to the last cycle Active Experimentation, the students bring along the positive learning outcomes from the scenario and the reflections as well as planning how to apply them in future clinical situations. Students, who have identified weakness, have formulated learning goals how to achieve the lack of knowledge and have described how they will act next time in similar clinical situations and in their future profession, which is in line with the general national learning goals recommended by Higher Education in Sweden, that the student should demonstrate the ability to identify his or her need for further knowledge and to develop competence.

It is important to give the student time for reflection to deepen the knowledge. After the high-fidelity simulation and the debriefing, the students got time to individually conduct an in-depth reflection. Before handle in the individual written academic reflection to the examiner, the students had two days to reflect on completed simulation scenarios. The students described an improved and deepened learning experience, since the academic reflection forced them to reflect upon clinical competence in performed simulated scenarios. According to Schön 
(1983) the students were asked to reflect during the simulation scenario in action. For example, the students could stop for a short moment and evaluate the clinical situation, "What do we have, what have we done and how do we go further". After the simulated scenario in the debriefing, the students reflect on action through CRM principals and learning objectives. When the students received motivational feedback from the teacher, the facilitator, and the observers, they became aware of their abilities. Finally, in the academic reflection, the students reflect on action but also reflect for action. Several students expressed that they could see their own progression and were able to put theory into practice more easily. For future profession, the students described that they were more aware of what action to take, how to do it, and why. However, some students expressed that they had learnt from their mistakes and will be better prepared next time.

A limitation of the study was that it was the first time for students to write an academic reflection. In course, in the evaluations, some students stated that they found it difficult to write an academic reflection. As lectures, we saw that there was a varied quality of the ability to reflect upon and analyse the concreate experience and how to relate to relevant literature. Critical and transformative reflective writing as a form of academic writing is difficult for students to master (Rodgers, 2002). Furthermore, students need to train to write academic reflections. Educators must implement that writing academic reflections take place early in the education and the students need to get feedback. Another limitation may have been that the academic reflection was an examination and that the judging lectures were the same persons who conducted the study.

\section{Conclusion}

The present study illustrates the impact an individual written academic reflection after a high-fidelity simulation can have on student nurses' learning experience of clinical competence. By implementing an examination that provides an opportunity for time for an in depth-reflection, creates effectively professional development.

The examination appeared to be a good learning experience as the questionnaire for the academic reflection forced the student to be aware of their own individual strengths and weaknesses and, on basis of this, identify the lack of knowledge and set goals to develop clinical competence. Simulation scenarios, in connection with a reflective tool, resulted in a gain of the students' own identification concerning the concept of clinical reasoning, patient safety, communication skills and teamwork.

The students appreciated being an observer because it was such a good learning experience. However, an observational instrument needs to be developed and validated to clarify what the observer should focus on in the simulation scenario in relation to the learning objectives.

By integrating reflective writing continuously during the nursing education, a reflective approach to student nurses' learning experiences can occur. This sys- 
tematically way to integrate reflective writing can contribute to the progression of students' skills to write an academic reflection.

\section{Acknowledgements}

The authors would like to express their gratitude to all nursing students in the courses who participated in the study. Thanks to the Center for Research on Welfare, Health and Sport (CVHI) at Halmstad University.

\section{Authors' Contributions}

$\mathrm{EF}$ and KR contributed equally to all aspects of the research and writing. Both authors read and approved the final manuscript.

\section{Authors' Information}

Elenita Forsberg, $\mathrm{PhD}, \mathrm{RN}$, is a senior lecturer in nursing and an educational leader at School of Health and Welfare, Halmstad University.

Karin Rasmusson, MNSc, RN, is a lecturer in nursing and an instructor for simulation scenarios at School of Health and Welfare, Halmstad University.

\section{Conflicts of Interest}

The authors declare no conflicts of interest regarding the publication of this paper.

\section{References}

Aiken, L., Clarke, S., Cheung, R., Sloane, D., \& Silber, J. (2003). Educations Levels of Hospital Nurses and Surgical Patient Mortality. JAMA, 290, 1617-1620.

https://doi.org/10.1001/jama.290.12.1617

Aiken, L., Sloane, D., Bruynell, L., Van den Heerde, K., Griffiths, P., Busse, R., Diomidous, M., Kinnunen, J., Kózka, M., Lesaffre, E., McHugh, M., Moreno-Casbas, M., Rafferty, A. M., Schwendimann, R., Scott, A., Carol Tishelman, C., Van Achterberg, T., Sermeus, W., \& RN4CAST Consortium (2014). Nurse Staffing and Education and Hospital Mortality in Nine European Countries: A Retrospective Observational Study. The Lancet, 383, 1824-1830. https://doi.org/10.1016/S0140-6736(13)62631-8

Aiken, L., Sloane, D., Griffiths, P., Rafferty, A. M., Bruynell, L., McHugh, M., Maier, C., Moreno-Casbas, T., Ball, J., Ausserhofer, D., Sermeus, W., \& RN4CAST Consortium (2017). Nursing Skill Mix in European Hospitals: Cross-Sectional Study of the Association with Mortality, Patient Ratings, and Quality of Care. BMJ Quality \& Safety, 26, 559-568. https://doi.org/10.1136/bmjqs-2016-005567

Alhaj Ali, A., \& Musalam, E. (2018). Debriefing Quality Evaluation in Nursing Simulation-Based Education: An Integrative Review. Clinical Simulation in Nursing, 16, 15-24. https://doi.org/10.1016/j.ecns.2017.09.009

Bryman, A. (2016). Social Research Methods (5 $5^{\text {th }}$ ed.). Oxford, 373-374.

Delany, C., \& Golding, C. (2014). Teaching Clinical Reasoning by Making Thinking Visible; an Action Research Project with Allied Health Clinical Educators. BMC Medical Education, 14, 20. https://doi.org/10.1186/1472-6920-14-20

Eikeland Husebø, S., Dieckmann, P., Rystedt, H., Søreide, E., \& Friberg, P. (2013). The 
Relationship between Facilitators' Questions and the Level of Reflection in Postsimulation Debriefing. Simulation in Healthcare, 8, 135-142. https://doi.org/10.1097/SIH.0b013e31827cbb5c

Fey, M. K., Scrandis, D., Daniels, A., \& Haut, C. (2014). Learning through Debriefing: Students' Perspectives. Clinical Simulation in Nursing, 10, e249-e256. https://doi.org/10.1016/j.ecns.2013.12.009

Fonteyn, M. E., \& Ritter, B. J. (2008). Clinical Reasoning in Nursing. In J. Higgs, M. A. Jones, S. Loftus, \& N. Christensen (Eds.), Clinical Reasoning in the Health Professions (3rd ed., p. 504). Oxford: Butterworth-Heinemann Ltd.

Graneheim, U. H., Lindgren, B. M., \& Lundman, B. (2017). Methodological Challenges in Qualitative Content Analysis: A Discussion Paper. Nurse Education Today, 56, 29-34. https://doi.org/10.1016/j.nedt.2017.06.002

Hellier, S., \& Davidson, L. (2018). Team Teaching in Nursing Education. The Journal of Continuing Education in Nursing, 49, 186-192. https://doi.org/10.3928/00220124-20180320-09

Jessee, M. A., \& Tanner, C. A. (2016). Pursuing Improvement in Clinical Reasoning: Development of the Clinical Coaching Interactions Inventory. Journal of Nursing Education, 55, 495-504. https://doi.org/10.3928/01484834-20160816-03

Johannesson, E., Silén, C., Kvist, J., \& Hult, H. (2013). Students' Experiences of Learning Manual Clinical Skills through Simulation. Advances in Health Sciences Education, 18, 99-114. https://doi.org/10.1007/s10459-012-9358-Z

Kolb, D. A. (1984). Experiential Learning: Experience as the Source of Learning and Development (Vol. 1). Englewood Cliffs, NJ: Prentice-Hall.

Lestander, Ö., Lehto, N., \& Engström, Å. (2016). Nursing Students' Perceptions of Learning after High Fidelity Simulation: Effects of a Three-Step Post-Simulation Reflection Model. Nurse Education Today, 49, 219-224. https://doi.org/10.1016/j.nedt.2016.03.011

Levett-Jones, T., Hoffman, K., Dempsey, J., Yeun-Sim Jeong, S., Noble, D., Norton, C. A., Roche, J., \& Hickey, N. (2010). The "Five Rights" of Clinical Reasoning: An Educational Model to Enhance Nursing Students' Ability to Identify and Manage Clinically "At Risk" Patients. Nurse Education Today, 30, 515-520. https://doi.org/10.1016/j.nedt.2009.10.020

Ministry of Social Affairs (2010). Patient Safety Act. https://www.riksdagen.se/sv/dokument-lagar/dokument/svensk-forfattningssamling/p atientsakerhetslag-2010659 sfs-2010-659

Moon, J. (2006). Learning Journals: A Handbook for Reflective Practice and Professional Development. London: Routledge. https://doi.org/10.4324/9780203969212

Notarnicola, I., Petrucci, C., Rosimar De Jesus Barbosa, M., Giorgi, F., Stievano, A., \& Lancia, L. (2016). Clinical Competence in Nursing: A Concept Analysis. Professioni infermieristiche, 69, 181-188.

Okuda, Y., Bryson, E., De Maria, S., Jacobseon, L., Quinones, J., Shen, B., \& Levine, A. (2009). The Utility of Simulation in Medical Education: What Is the Evidence? Mount Sinai Journal of Medicine, 76, 330-343. https://doi.org/10.1002/msj.20127

Østergaard, D., Dieckmann, P., \& Lippert, A. (2011). Simulation and CRM. Best Practice \& Research Clinical Anaesthesiology, 25, 239-249. https://doi.org/10.1016/j.bpa.2011.02.003

Pelger, S., \& Larsson, M. (2018). Advancement towards the Scholarship of Teaching and Learning through the Writing of Teaching Portfolios. International Journal for Academic Development, 23, 179-191. https://doi.org/10.1080/1360144X.2018.1435417 
Pelger, S., \& Santesson, S. (2017). Kompetensportfölj för dokumentation, reflektion och progression. Report EQ11-projektet, Lund: Lund University. http://www.naturvetenskap.lu.se/files/portfoljrapport.pdf

Rodgers, C. (2002). Defining Reflection: Another Look at John Dewey and Reflective Thinking. Teachers College Record, 104, 842-866. https://doi.org/10.1111/1467-9620.00181

Ryan, M. (2011). Improving Reflective Writing in Higher Education: A Social Semiotic Perspective. Teaching in Higher Education, 16, 99-111. https://doi.org/10.1080/13562517.2010.507311

Schön, D. A. (1983). The Reflective Practitioner: How Professionals Think in Action. New York: Basic Books.

Shinnick, M. A., Woo, M., Horwich, T. B., \& Steadman, R. (2011). Debriefing: The Most Important Component in Simulation? Clinical Simulation in Nursing, 7, e105-e111. https://doi.org/10.1016/j.ecns.2010.11.005

Wotton, K., Davis, J., Button, D., \& Kelton, M. (2010). Third-Year Undergraduate Nursing Students' Perceptions of High-Fidelity Simulation. Journal of Nursing Education, 49, 632-639. https://doi.org/10.3928/01484834-20100831-01 